\title{
Influence of Dregea sinensis Hemsl. protease on the quality of mozzarella cheese from buffalo milk
}

\author{
Hongyan Wang ${ }^{1,2}$, Yujing Wang ${ }^{1}$, Aixiang Huang ${ }^{1 *}$ \\ ${ }^{1}$ College of Food Science and Technology, Yunnan Agricultural University, Kunming, Yunnan, China, ${ }^{2}$ School of Food Science and \\ Engineering, Hefei University of Technology, Hefei, China,
}

\section{A B S T R A C T}

\begin{abstract}
In this study, Dregea sinensis Hemsl. protease called chymosin was extracted and purified from $D$. sinensis Hemsl. stalk and was used for mozzarella cheese production. Calf rennet and microbial chymosin were used as the control group SDS-PAGE revealed that $D$. sinensis Hemsl. protease can be used to produce mozzarella cheese as it degrades $\alpha$-casein of buffalo milk. Volatile acids and carbonyl compounds are the main sources of the flavor in mozzarella cheese. Thus, fifty-two flavor substances were detected through GC-MS. Fresh and sweet glutamic acid and histidine were the dominant free amino acids in examined cheese $(P<0.05)$. Texture profile analysis indicated that the produced cheese was more restorative and flexible compared to the control group. Scanning electron microscopy demonstrated that the produced cheese was smooth, as indicated by the small pore cross-section diameter of mozzarella cheese and its close net structure. Therefore, D. sinensis Hemsl. can be applied to process cheese
\end{abstract}

Key words: Dregea sinensis Hemsl; Protease; Mozzarella cheese quality; Protein degradation; Flavor and texture parameters

\section{INTRODUCTION}

Dregea sinensis Hemsl. is a wild vine growing in mountain forests at 500-3000 m elevation, in northwest Yunnan, China. The hydrothermal solution of this plant's stalk has been used as a coagulant to process cheese (Xue, 1994; Wu, 2003). The milk coagulant of D. sinensis Hemsl. is composed of protease, Which cleaved $x-\mathrm{CN}$ at $\mathrm{Ala} 90-\mathrm{G} \ln 91$ and produced deputy $x-\mathrm{CN}$ and caseinomacropeptide with molecular weights of 12 and $6.9 \mathrm{kDa}$, respectively (Ma, 2013; Tao, 2014; Zhang, 2015). However, the application of $D$. sinensis Hemsl. to produce mozzarella cheese from buffalo milk has yet to be investigated.

The plant protease rennin-like enzyme has been extensively investigated (Su et al., 2009; Ben Amira A et al., 2017). The protease of aspartic extracted from cardoon which found that this enzyme exhibits a strong proteolytic activity and breaks the peptide bond between Phe105 and Met106 of $x$-CN. Galán et al. (2008) investigated the effects of different dosages of aspartic protease on the quality of cheese and showed that cardoon rennin can improve the sensory quality and shorten the maturation time of feta cheese. The protease extracted from fresh ginger which observed that this enzyme exhibits a strong coagulating activity and hydrolyzes $\alpha, \beta$, and $x-\mathrm{CN}$. This protease can effectively degrade $\alpha-\mathrm{CN}$ (Huang et al., 2011). This enzyme is also more specific to $x-\mathrm{CN}$ than to the two other types. Hashim (2011) prepared Peshawari cheese with improved sensory characteristics, namely, appearance, texture, and taste by using ginger protease $(\mathrm{P}<0.05)$ and the most important is that the cheese bitterness has been removed. Ivana Puglisi (2014) found that the water solution of kiwi fruit can be used as a source of plant rennin to produce mozzarella cheese because this enzyme can improve flavor and reduce the amount of the peptide causing bitterness. Moni Kumari et al. (2012) and Ahmed et al. (2009a, 2009b) purified a new serine protease from bodhi tree which exhibits a strong coagulating activity; three weeks of after-ripening, the texture and flavor of mature soft cheese from milk were equal to those of cheese from calf rennet. M. oleifera flowers contain caseinolytic and milk-clotting activities, which is a new source of plane proteases with potential use for cheese production, since it promotes extensive hydrolysis of $x$-casein and low degradation of $\alpha$ s- and $\beta$-caseins (Pontual et al., 2012). The use of these

\footnotetext{
*Corresponding author:

Aixiang Huang, College of Food Science and Technology, Yunnan Agricultural University, Kunming 650201, Yunnan, China.

Telephone: 0086-13769132115; Fax numbers: 0086-0871-63649220; E-mail: aixianghuang@126.com
} 
plant proteinases as milk coagulants is very interesting since they are natural enzymes and can also be used for producing cheeses aimed at lacto-vegetarian consumers and ecological markets (Gómez et al., 2001). They can also be used for Kosher and Halal products.

With the increased production of cheese, the demand for rennin-like enzymes has also increased. As such, plant protease has been considered as a new resource. In this study, D. sinensis Hemsl. Protease (DHP) was used to produce mozzarella cheese and it was also compared with traditional calf rennet (CR) and microbial rennin (MR). The influence of this protease on the quality of cheese was investigated. The potential application was investigated by analyzing the protein degradation, flavor substances, and microtexture characteristics of mozzarella cheese.

\section{MATERIALS AND METHODS}

\section{Experimental materials}

D. sinensis Hemsl. protease (DHP) was extracted from the water solution of D. sinensis Hemsl. Stalk. Each stem was divided into 20 pieces, soaked in warm water at $55^{\circ} \mathrm{C}$ for $30 \mathrm{~min}$, cooled, filtered, and then vacuum concentrated to $20 \%$ of the original volume at $55^{\circ} \mathrm{C}$. The concentrate was allowed to stand for $24 \mathrm{~h}$ at $4{ }^{\circ} \mathrm{C}$ before salt fractionation. The salting-out protein ( $40 \%$ ammonium sulfate) with the highest milk-clotting activity was selected, dialyzed, and purified for $4 \mathrm{~h}$ with a MW 3500 dialysis bag (dialysis tubing 3500 , Sigma Co.) at 0 to $4{ }^{\circ} \mathrm{C}$. This process was carried out 3 times. The purified protein was vacuum freezedried to produce powder and preserved at $-20^{\circ} \mathrm{C}$. Purification of Protease in accordance with the methods described by Zhang Yali (2015). Calf rennet (CR) and microbial rennin (MR) were purchased from SACOO, Ltd. Caseins (CN), a-casein $(\alpha-C N), \beta$-casein $(\beta-C N)$, and $x$-casein $(x-C N)$ were obtained from Sigma-Aldrich. All of the reagents were analytically pure.

\section{Preparation of mozzarella cheese from buffalo milk}

Fresh raw buffalo milk was obtained from the Bright Dairy Farm, Dali, China. The milk was split into three lots. One lot was used for cheese making with DHP $\left(4 \mathrm{~g} \cdot 100 \mathrm{~L}^{-1}\right.$ milk), the two other lots were used for cheese production using CR $\left(3 \mathrm{~g} \cdot 100 \mathrm{~L}^{-1}\right.$ milk $)$ and MR $\left(0.35 \mathrm{~g} \cdot 100 \mathrm{~L}^{-1}\right.$ milk $)$. The experiment was replicated three times. Before cheese production, milk was pasteurized at $75{ }^{\circ} \mathrm{C}$ for seconds. Specific fermentation cultures mixed equal volumes (12.5 g $\cdot 50 \mathrm{~L}^{-1}$ milk; Lactobacillus bulgaricus and Streptococcus thermophilus (1:1); Hansen, TCC-3) of mozzarella cheese were added to $50 \mathrm{~L}$ of buffalo milk after pasteurization was completed. The mixture was pre-acidified until $\mathrm{pH}$ that reached 6.2 then the milk curd for batches which clotting with DHP, CR and MR respectively, and fermented it until that $\mathrm{pH}$ reached 4.9. The fermented product was cut, drained, and pilled for $10 \mathrm{~min}$. The fermented product was hot-stretched at $85^{\circ} \mathrm{C}$ and draining of whey. Afterward, it was packaging in pouches and storing in $2-8{ }^{\circ} \mathrm{C}$ for later use. For analysis, These samples were developed with five replications for find out better results.

\section{Analysis of the protein degradation in cheese}

The methods used in this study were based on a modified procedure described by Andrews (1983). The SDS-PAGE was conducted to analysis the protein degradation in cheese with D. sinensis proteases (12\% separationgel, $4 \%$ concentration gel). The electrophoretic conditions were as follows: spacer gel at $50 \mathrm{~V}$ and separation gel at 120 $\mathrm{V}$. The sample was pre-treated in accordance with the following procedures. Vacuum-freeze-dried sediment with a $\mathrm{pH}$ of 4.6 was dissolved in the sample buffer solution; the solution was thoroughly mixed and heated in boiling water for $5 \mathrm{~min}$. The sample was cooled and subsequently loaded. Coomassie brilliant blue (G-250, Bio-Rad) was used to dye glue tapes (Cao et al., 2016). An automatic imaging system (Protein simple, USA) was used to expose the dyed glue tapes. AlphaView SA was used to quantitatively analyze the electrophoretic bands. The intact rate of $\mathrm{CN}$ is the ratio of the optical density of each band to that of the whole standard sample. The decomposition rate of $\mathrm{CN}$ was calculated as follows: $\mathrm{CN}=100 \%$ - intact rate.

\section{Analysis of the flavor substances of cheese Free amino acids}

The free amino acids of the cheese were determined by using an amino acid analyzer (Hitachi L-8900, Japan) in accordance with the guidelines of GB/T 5009.124-2003 Determination of Amino Acids in Foods.

Analysis of the volatile flavor components of cheese Solid-phase micro-extraction was conducted to detect samples. GC-MS (7890A-5975C, Agilent, USA) was used to separate and determine volatile flavor components. The sample [5 $\mathrm{mL}(\mathrm{g})]$ was placed in a $15 \mathrm{~mL}$ headspace bottle, and a $75 \mu \mathrm{m}$ aged Car/PDMS extraction head was inserted into the head space of the sample bottle to adsorb the sample for $30 \mathrm{~min}$ at $50{ }^{\circ} \mathrm{C}$. Subsequently, the head was inserted into the injection port of the gas chromatograph to perform adsorption for $3 \mathrm{~min}$ at $250^{\circ} \mathrm{C}$. In this process, the instrument started to collect data.

\section{Texture profile analysis (TPA) Sensory TPA}

The texture of mozzarella cheese was determined in accordance with Saint-eve (2009); a columnar cheese sample was withdrawn by using a specific puncher along the fiber direction and placed in the center of a compact 
disk with the fiber oriented perpendicular to the disk. Each sample was evaluated six times. The parameters of a TA-XT2 texture analyzer (Stable Micro Systalk, Godalming, Surrey, UK) were set as follows: the samples were cut into small pieces with a dimension of $2 \mathrm{~cm} \times$ $2 \mathrm{~cm} \times 2 \mathrm{~cm}$. The probe specifications were as follows: T-shaped probe diameter, $38 \mathrm{~mm}$; compression, $50 \%$; and decreasing velocity, $100 \mathrm{~mm} / \mathrm{min}$. The primary mechanical characteristics of hardness, adhesiveness, cohesiveness and springiness were calculated from the two successive uniaxial compression cycles of TPA. The secondary characteristic of gumminess (hardness $\times$ cohesiveness) and chewiness

(hardness $\times$ cohesiveness $\times$ springiness) was then calculated.

\section{Microstructure analysis}

The samples were cut into small pieces measuring approximately $4-5 \mathrm{~mm}^{3}$ by using sharp double-edged blades and placed in a refrigerator $\left(4^{\circ} \mathrm{C}\right)$ for $24 \mathrm{~h}$ after $2.5 \%$ glutaraldehyde with a $\mathrm{pH}$ of 6.8 was added. These pieces were frozen in liquid nitrogen, and their cross sections were cut off with a blade. The samples were washed with phosphate buffer ( $\mathrm{pH}$ 6.8) thrice for $10 \mathrm{~min}$ at each time. The samples were dehydrated once with $30 \%, 50 \%, 70 \%$, and 90\% ethyl alcohol for 10-15 min at each time and then thrice with 100\% ethyl alcohol for 10-15 min at each time. The samples were degreased for $2 \mathrm{~h}$ with chloroform and shaken at intervals. Afterward, the samples were freeze-dried and plated with gold through physical vapor deposition. The faces were fixed and observed under a scanning electron microscope (SEM, SU1510, JEOL).

\section{Statistical analysis}

The data were statistically analyzed using the SPSS ver. 20 software package (SPSS Inc., Chicago, IL, USA). Twofactor ANOVA (Tukey's, test, significant level $P<0.05$ ) was taken into account to determine the significant differences among the different cheeses in terms of type of coagulant enzymes.

\section{RESULTS AND DISCUSSION}

\section{Analysis of the protein degradation level of cheese made using $D$. sinensis Hemsl. protease}

The SDS-PAGE analysis results of the cheese produced with DHP, CR and MR (Fig. 1). Zone 1 contains $\alpha_{\mathrm{s} 1}-\mathrm{CN}$ and $\alpha_{\mathrm{s} 2}-\mathrm{CN}$. Zone 2 mainly comprises $\beta-\mathrm{CN}$. Zone 3 includes $x-\mathrm{CN}$, which exists in cow milk. The colors of $\alpha-\mathrm{CN}, \beta-\mathrm{CN}$, and $x-\mathrm{CN}$ bands in Lane 4 are lighter than those in Lanes 5 and 6 . These findings indicated that $\alpha-\mathrm{CN}$, $\beta-\mathrm{CN}$, and $x-\mathrm{CN}$ in casein were degraded at different levels (Fig. 1). The changes in the band concentrations in the SDS-PAGE electrophoretogram were analyzed by using AlphaView SA. The relative degradation rates of different cheese proteins were obtained. After Lanes 4-6 were quantized, the changes and relative degradation rates were clearly observed from the relative peak area of the spectral concentration (Fig. 2). The analysis results of DHP (Lane 4, Fig. 2) revealed that the peak area of $\alpha-C N$ is the smallest; therefore, the degradation rate of $\alpha-\mathrm{CN}$ is the largest. The degradation rates were observed in the following order: $\alpha-\mathrm{CN}>\beta-\mathrm{CN}>x-\mathrm{CN}$. Lane 5 was compared with Lane 6 . The result demonstrated that the degradation rates of $\alpha-\mathrm{CN}$ and $\beta-\mathrm{CN}$ in cheese produced with DHP were higher than those in cheese produced with $\mathrm{CR}$ and MR. The degradation of $\alpha-\mathrm{CN}$ is a relevant reaction that changes the structure of cheese and initially transforms its texture (Merheb-Dini et al., 2016). The hydrolysis rate of $\alpha-\mathrm{CN}$ is higher than those of the two other enzymes. As a result, the protein network structure changes; hence, cheese gradually softens (Fang et al., 2016). The specificity of DHP in protein degradation indicates that this enzyme is suitable for cheese production..

\section{Analysis of the flavor substances in the cheese Contents of the free amino acids in the cheese}

As shown in Table 1, different varieties, relative contents, and total contents of free amino acids were detected in DHP cheese. The contents of ASP, SER, and HIS were detected more higher in the DHP group. By contrast, ASP and SER were not detected in CR and MR groups. The contents of MET and TYR in the three groups were not significantly different $(P>0.05)$. Among the amino acid of GLY, PRO, ALA, and SER contribute to the sweet taste, and GLU contributes to the delicate flavor. HIS, ASP, SER, and LEU are the major contributors to the flavor. After pyrolysis occurs, CYSe, CYS, and MET can produce some flavor compounds, which are major substances influencing the delicate flavor of food. The analysis revealed that

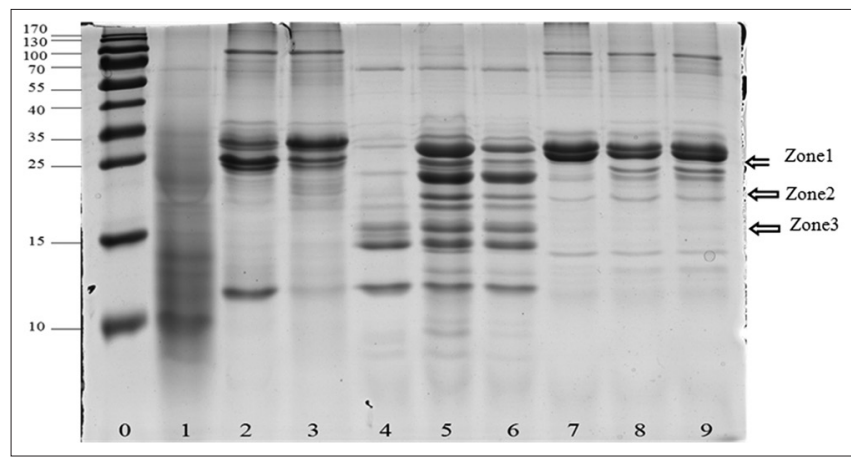

Fig 1. The SDS-PAGE of the PH4.6-insoluble fractions of the cheeses made using $D$. sinensis Hemsl. Protease (DHP), calf rennet (CR) and microbial rennin (MR). Lane 0 , marker. Lanes $1-3, D H P+C N$, $\mathrm{CR}+\mathrm{CN}$, and $\mathrm{MR}+\mathrm{CN}$, respectively. Lanes 4-6, electrophoretic bands of $\mathrm{pH}$ 4.6-soluble nitrogen in cheese produced with DHP, CR, and MR, respectively. Lanes 7-9, electrophoretic bands of $\mathrm{pH}$ 4.6-insoluble nitrogen in cheese produced with DHP, CR, and MR, respectively. 


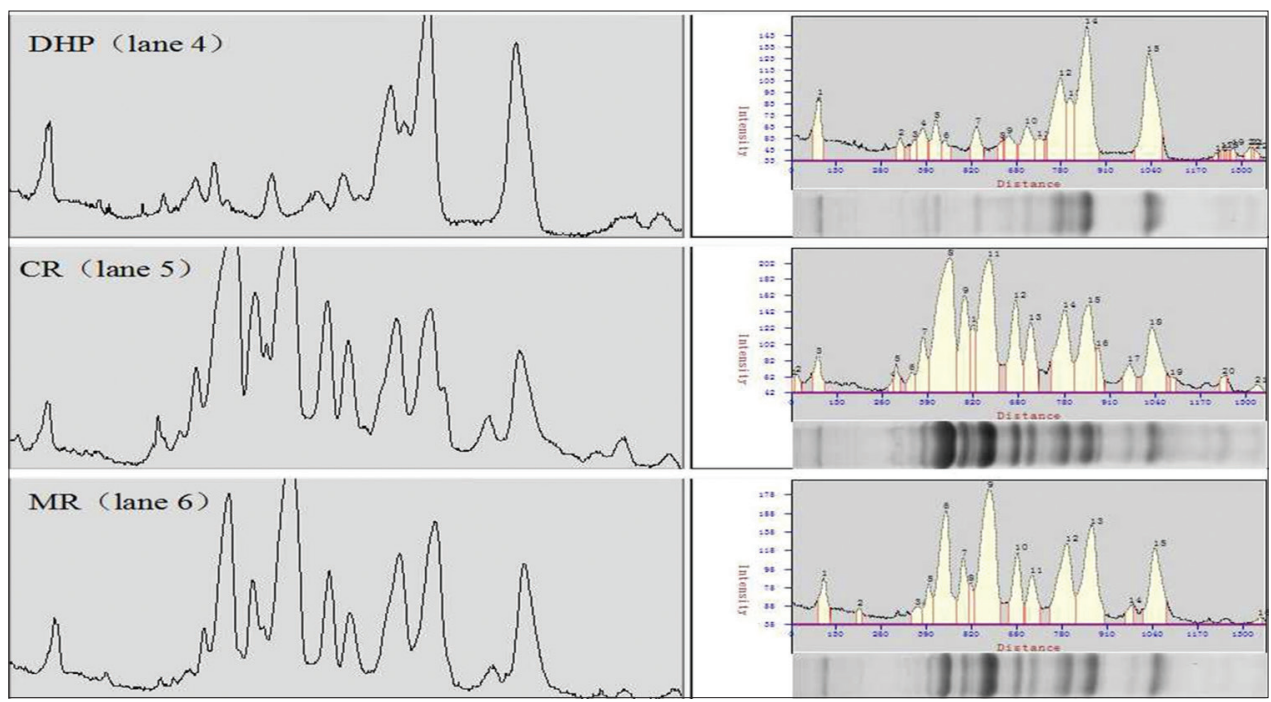

Fig 2. Analysis on the degradation rates of protein and peptide fragments in lanes 4-6.

\begin{tabular}{|c|c|c|c|}
\hline Amino acids & DHP (\%) & CR (\%) & MR (\%) \\
\hline ASP & $2.62 \pm 0.33$ & - & - \\
\hline${ }^{*} \mathrm{THR}$ & $4.65 \pm 0.02^{c}$ & $14.66 \pm 1.51^{b}$ & $17.18 \pm 0.26^{a}$ \\
\hline SER & $1.17 \pm 0.13$ & - & - \\
\hline GLU & $31.05 \pm 0.58^{b}$ & $34.12 \pm 2.02^{\mathrm{a}}$ & $29.97 \pm 1.32^{c}$ \\
\hline GLY & $2.91 \pm 0.09^{a}$ & $1.39 \pm 0.02^{b}$ & $0.27 \pm 0.01^{c}$ \\
\hline ALA & $4.37 \pm 0.46^{a}$ & $4.86 \pm 0.78^{b}$ & $3.99 \pm 0.23^{b}$ \\
\hline $\mathrm{CYS}^{* *}$ & $4.49 \pm 0.01^{b}$ & $2.94 \pm 0.96^{c}$ & $5.40 \pm 1.03^{\mathrm{a}}$ \\
\hline $\mathrm{VAL}^{*}$ & $5.70 \pm 0.77^{c}$ & $19.84 \pm 1.21^{b}$ & $20.62 \pm 2.38^{a}$ \\
\hline MET $^{*}$ & $4.40 \pm 0.76^{b}$ & $4.14 \pm 1.03^{b}$ & $4.88 \pm 0.63^{a}$ \\
\hline ILE $^{*}$ & $6.62 \pm 1.04^{\mathrm{a}}$ & $14.62 \pm 0.78^{b}$ & $15.51 \pm 2.63^{b}$ \\
\hline LEU $^{*}$ & $4.10 \pm 1.89^{c}$ & $13.53 \pm 1.11^{b}$ & $14.50 \pm 0.95^{\mathrm{a}}$ \\
\hline $\mathrm{TYR}^{\star *}$ & $5.80 \pm 0.02^{a}$ & $4.36 \pm 1.65^{\mathrm{ab}}$ & $4.25 \pm 0.53^{b}$ \\
\hline $\mathrm{PHE}^{*}$ & $8.83 \pm 0.28^{c}$ & $10.39 \pm 1.30^{\mathrm{a}}$ & $9.18 \pm 0.97^{b}$ \\
\hline LYS & $14.61 \pm 0.25^{c}$ & $20.33 \pm 1.65^{a}$ & $18.83 \pm 2.39^{b}$ \\
\hline $\mathrm{HIS}^{\star \star *}$ & $37.30 \pm 2.47^{a}$ & $17.51 \pm 1.06^{b}$ & $13.59 \pm 0.82^{c}$ \\
\hline $\mathrm{ARG}^{* * *}$ & - & - & - \\
\hline PRO & $8.08 \pm 2.13^{b}$ & $12.45 \pm 3.01^{\mathrm{a}}$ & $10.92 \pm 1.58^{a}$ \\
\hline $\begin{array}{l}\text { Total } \\
\text { content }(\mathrm{mg} / \mathrm{kg})\end{array}$ & $146.70 \pm 11.16^{b}$ & $175.14 \pm 18.98^{a}$ & $169.09 \pm 17.93^{\mathrm{ab}}$ \\
\hline
\end{tabular}

${ }^{*}$ Essential amino acids, ${ }^{* *}$ semi-essential amino acids, ${ }^{* * *}$ essential amino acids for infant growth; a Means of the same parameter in the same row without a common superscript letters $(a-c)$ differ significantly $(P<0.05)$

D. Sinensis Hemsl. releases various free amino acids during cheese production. The amino acids contents affecting the flavor of the cheese are not significantly different from those of traditional rennin. This result indicated that DHP can improve the flavor in cheese production; hence, this enzyme can be applied to produce cheese.

\section{Volatile flavor substances in the cheese}

Volatile flavoring substances of cheese were analyzed; mass spectrograms of examined samples are shown in Fig. 3.
Based on matching with the NIST08 of mass spectrogram database and analysing artificial, the chemical components of the flavor substances were determined. Moreover, the relative mass percentage and variety of these components were obtained through area normalization method, and the results are displayed in Table 2.

In the DHP group, 52 flavor compounds, including 8 hydrocarbons, 5 alcohols, 8 aldehydes, 4 acids, 15 esters, 4 ketones, and 8 others, were detected. Gómez-Ruiz et al. (2008) also identified and classified the flavor compounds of cheese. The authors found that the flavor is formed mainly by esters, alcohols, ketones and other substances, and this finding is consistent with our results. Delgado et al. (2011) reported that butyric acid, octanoic acid, and capric acid can be used to determine the quality of butterfat flavor, which is related to the scent of cheese. A higher content of these acids indicate a better quality (McCarthy et al., 2017; Ali et al., 2017). In the current experiment, the contents of butyric acid, octanoic acid, and capric acid were higher in the DHP group than in the other groups. DHP cheese contained an altered fat type and significantly influenced the formation of long- and short-chain free fatty acids, as well as the type of free fatty acid, which hexadecanoic acid, pentanoic acid and cyclopentaneundecanoic acid were more content of detection than control group (Table 2). Four additional flavor compounds, namely, 1-hexanol, 3-methyl-2-butanone, methyl ketone, and cotyl aldehyde, were detected in the DHP group. With the fruit aroma of 1-hexanol, sweet or butter odor of methyl ketone, and fat or citrus odor of cotyl aldehyde (George, 2004), these compounds can improve and enrich the flavor of cheese. The kind of aldonetone compounds of 2-Decanone and Octanal were increased in cheese by making DHP. 

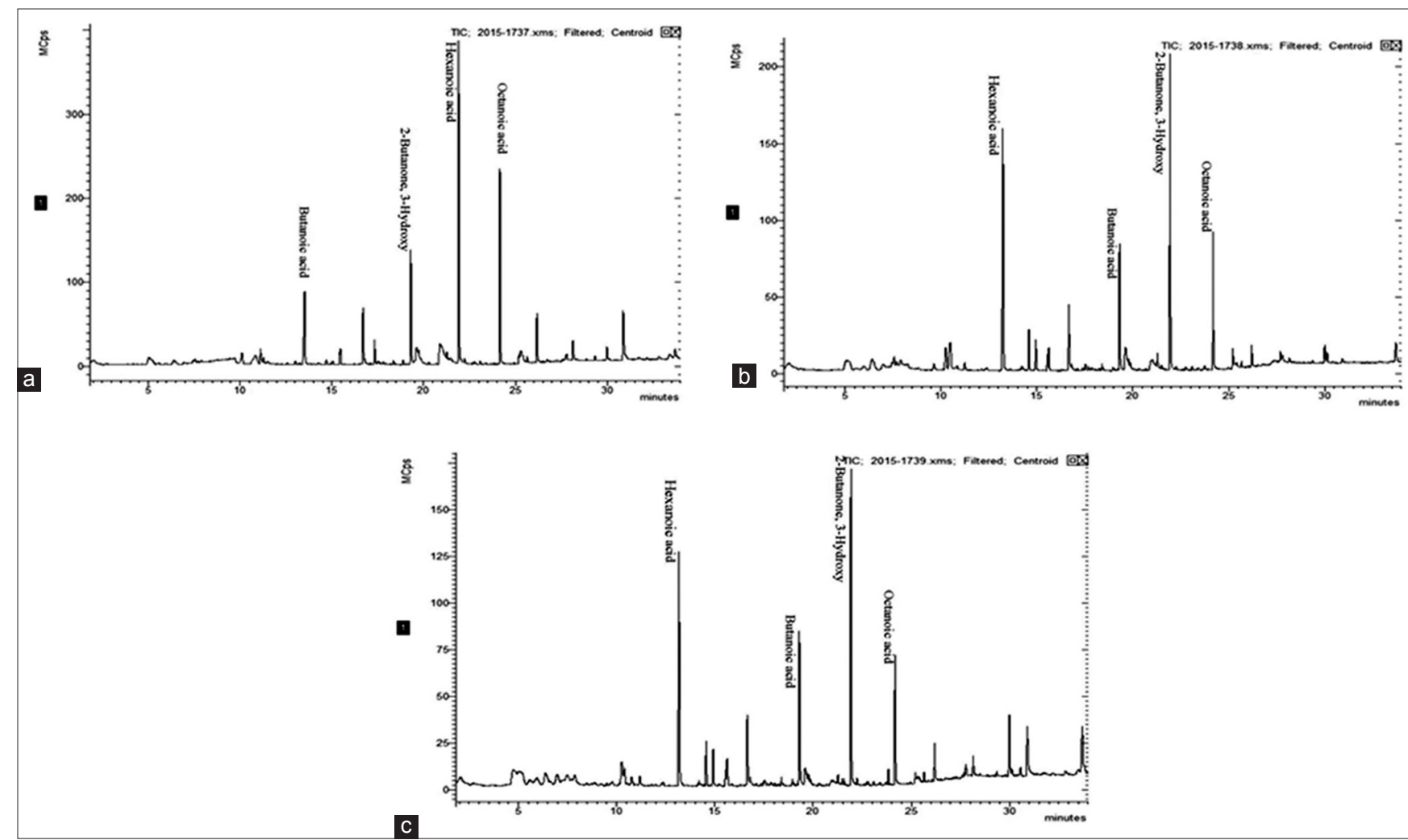

Fig 3. Chromatogram of volatile flavor compounds in buffalo mozzarella cheese made with different kinds of rennet. (a) $D$. sinensis Hemsl. Protease (DHP); (b) calf rennet (CR); (c) microbial rennin (MR).

\section{Analysis of the influence of DHP on cheese texture TPA determination results}

The texture parameters of mozzarella cheese in the DHP group was shown in Table 3. The hardness and gumminess of cheese in the DHP group were significantly compared to the control group $(P<0.05)$. Hardness depends on nonfat solids, and differences in texture are related to the degradation level of protein (Ahmed et al., 2005, Zisu et al., 2007). The higher level degradation in the DHP group enabled the protein to form a dense net structure; hence, the cheese can recover better after compression; consequently, the cheese is harder, which shows the stronger deformation resistance of cheese composed of DHP with a stronger gelatin system. The gumminess of this cheese reflects that it cannot be easily chewed into small pieces for swallowing so that it can stay complete. The resilience in the DHP group is not significantly different $(P>0.05)$ from that in the CR group; this finding indicated that the constant resistivity of DHP cheese is similar to that of classic MR cheese. The cohesiveness of the DHP cheese is also not significantly different $(P>0.05)$. Therefore, the mechanical structure of casein micelle in DHP cheese is similar to that in control group cheese. The stronger hardness and springiness of DHP cheese and the similar springiness and cohesiveness in the DHP group to those in the CR group suggested that DHP can be used in cheese production as a rennin substitute.

\section{Analysis on the microstructure of cheese}

The microstructure changes in the three group cheeses were observed through SEM (Fig. 4). Compared with the control group (Fig. 4b and c), DHP can degrade casein in cheese; thus, the colloidal particles aggregated inside the cheese were degraded into smaller aggregates and the protein colloidal particles decreased in size to form smaller clearance space; consequently, the net structure became denser to form a compact, smooth, and uniform a shape (Fig. 4a). DHP cheese has similar structure to that of (Fig. 4c) MR cheese, but the smaller and finer holes in the former indicates that DHP can improve the texture of mozzarella cheese. Jooyandeh et al. (2017)observed the influence of fat reduction on the microstructure of cheese through SEM. Their observation has revealed that the microstructure changes with the reduction of fat, and the protein network becomes dense and compact. Ayala-Bribiesca et al. (2016) observed the effects of the different contents of calcium and water on the structure and function of cheese through SEM. These parameters showed that structural changes are associated with functional changes.

\section{CONCLUSIONS}

D. sinensis Hemsl. protease can degrade $\mathrm{CN}$ in mozzarella at different levels, which are higher than in the control 
Table 2: Varieties of volatile flavor substances in cheese produced with D.sinensis Hemsl. Protease (DHP), calf rennet (CR) and microbial rennin (MR)

\begin{tabular}{|c|c|c|c|c|c|c|c|}
\hline $\begin{array}{l}\text { Volatile } \\
\text { compounds }\end{array}$ & DHP (\%) & CR (\%) & MR (\%) & $\begin{array}{l}\text { Volatile } \\
\text { compounds }\end{array}$ & DHP (\%) & CR (\%) & MR (\%) \\
\hline Ketones (17) & 8 & 7 & 10 & $\begin{array}{l}\text { Benzaldehyde, } \\
\text { 3-benzyloxy-2-fluoro-4-met }\end{array}$ & - & 2.992 & - \\
\hline 2,3-Butanedione & 0.857 & 1.999 & 0.115 & 2-Butenal, 3-methyl- & - & 0.101 & - \\
\hline 2-Butanone, 3-methyl- & 2.043 & - & - & Benzaldehyde & - & - & 0.38 \\
\hline 2-Heptanone & 1.631 & 2.711 & 3.084 & 2-Nonenal, (E)- & - & - & 0.151 \\
\hline 2-Butanone, 3-hydroxy & 8.196 & 18.37 & 15.7 & Acids (19) & 15 & 11 & 12 \\
\hline 2-Hydroxy-3-pentanone & 0.313 & 2.276 & 2.149 & Acetic acid & 4.893 & 4.803 & 4.353 \\
\hline 2-Nonanone & 0.689 & 0.911 & 0.998 & Butanoic acid & 7.639 & 7.197 & 8.353 \\
\hline 2-Undecanone & 0.226 & 0.155 & 0.227 & Cyclopentaneundecanoic acid & 0.046 & - & - \\
\hline 2-Dodecanone & 0.088 & - & - & Pentanoic acid & 0.112 & - & - \\
\hline 2,3-Pentanedione & - & 0.98 & - & Hexanoic acid & 19.63 & 16.3 & 14.37 \\
\hline 2-Pentanone, 3-methyl- & - & - & 1.609 & Heptanoic acid & 0.239 & 0.252 & 0.156 \\
\hline 3-hydroxy-2-pentanone & - & - & 2.502 & Octanoic acid & 11.6 & 7.24 & 6.012 \\
\hline 2-Tridecanone & - & - & 0.236 & Nonanoic acid & 0.131 & 0.931 & 0.374 \\
\hline 2-Pentadecanone & - & - & 0.623 & Hexadecanoic acid & 1.655 & & \\
\hline Hydrocarbon (15) & 5 & 5 & 5 & n-Decanoic acid & 3.196 & 1.2 & 1.91 \\
\hline Cyclotetrasiloxane, octamethyl- & 0.116 & 0.097 & - & 3-Decenoic acid, (E)- & 0.092 & & \\
\hline Decane & 0.311 & - & - & Dodecanoic acid & 1.633 & 0.367 & 1.299 \\
\hline Cyclopentasiloxane, decamethyl- & 0.069 & - & 0.148 & Tetradecanoic acid & 5.596 & - & 4.445 \\
\hline $\begin{array}{l}\text { Cyclohexasiloxane, } \\
\text { dodecamethyl- }\end{array}$ & 0.025 & - & - & Pentadecanoic acid & 0.336 & - & 0.276 \\
\hline Pentadecane & 0.186 & & - & Octadecanoic acid & 1.291 & - & 0.575 \\
\hline Hexadecanal & - & 0.083 & - & Cyclopropanecarboxylic acid & - & 0.734 & 0.442 \\
\hline .alpha.-Pinene & - & 0.698 & - & $\begin{array}{l}\text { Acetic acid, trifluoro } \\
\text {-, 3,7-dimethyloct }\end{array}$ & - & 0.165 & - \\
\hline 1-Octene & - & 0.364 & - & 9-Octadecenoic acid (Z)- & - & 0.338 & - \\
\hline 3-Cyclopropyl-1-butyne & - & 0.213 & - & Esters (16) & 8 & 9 & 8 \\
\hline Heptane, 2,2,4,6,6-pentamethyl- & - & - & 0.147 & Silanediol, dimethyl- & 3.262 & - & - \\
\hline Dodecane, 2-methyl- & - & - & 0.51 & 2H-Pyran-2-one, tetrahydro-6-propyl- & 0.063 & 0.136 & - \\
\hline Heptadecane & - & - & 0.191 & Delta-Decalactone & 0.379 & - & - \\
\hline 5-Tridecene, (Z)- & - & - & 0.218 & $\delta$-Decalactone & & 0.323 & - \\
\hline Alcohols (15) & 8 & 7 & 10 & Octadecanoic acid, ethyl ester & 0.076 & - & - \\
\hline 3-Pentanol & 0.445 & - & - & methyl-9,9,10,10-D4-octadecanoate & 0.097 & - & 0.136 \\
\hline 1-Hexanol & 0.121 & - & 0.137 & 9-Octadecenoic acid (Z)-, methyl ester & 0.373 & - & - \\
\hline 2-Ethyl hexanol & 1.772 & 0.145 & - & Eicosanoic acid, methyl ester & 1.257 & 1.334 & 4.126 \\
\hline 1-Octanol & 0.317 & & - & Docosanoic acid, methyl ester & 1.52 & 2.16 & 5.138 \\
\hline Benzeneethanol & 0.103 & 0.262 & 0.101 & Acetic acid ethenyl estervinyl acetate & - & 2.002 & - \\
\hline 1-Butanol & 0.171 & 0.607 & - & Carbonic acid, methyl octyl ester & - & 0.766 & 0.751 \\
\hline 1-Butanol, 3-methyl- & 0.0172 & 0.696 & 0.708 & $\begin{array}{l}\text { hexadecanoic acid, } 1,1- \\
\text { Dimethyl ethyl ester }\end{array}$ & - & 0.712 & 0.213 \\
\hline 2-Buten-1-ol, 3-methyl- & 0.0111 & 0.356 & 0.222 & 11-octadecenoic acid methyl ester & - & 0.375 & 0.242 \\
\hline 1-Heptanol & - & 0.207 & - & Heptane, 2-methyl-2-butyl ester & - & & 0.277 \\
\hline 3-Buten-1-ol, 3-methyl- & - & - & 0.211 & Octadecanoic acid, butyl ester & - & 0.935 & - \\
\hline 1-Pentanol & - & - & 0.356 & $\begin{array}{l}\text { 3-Isopropoxy-1,1,1,7,7,7 } \\
\text {-hexamethyl-3,5, r }\end{array}$ & - & & 0.065 \\
\hline 1-Octanol & - & - & 0.506 & Others (13) & 4 & 6 & 4 \\
\hline 1-Heptadecanamine & - & - & 0.071 & Benzene, methyl- & 0.839 & & 1.417 \\
\hline Silanediol, dimethyl- & - & 3.752 & 2.502 & Pyridine & 3.194 & 4.064 & 1.355 \\
\hline 1-Dodecanol, 3,7,11-trimethyl- & - & - & 0.329 & Methoxy, Phenyl-, oxime & 6.685 & 1.468 & 0.171 \\
\hline Aldehydes (9) & 4 & 3 & 3 & 5'-O-(4-Oxopentanoyl)-2'-O-uridine & 0.364 & - & - \\
\hline Octanal & 0.342 & - & & Hydroxyurea & - & 0.048 & - \\
\hline Nonanal & - & 1.416 & 1.981 & 1-Tetradecanamine, N, N-dimethyl- & - & 0.199 & - \\
\hline 2-Octenal & 0.064 & - & - & Phenol, 2,5-bis (1,1-dimethylethyl)- & - & 0.065 & - \\
\hline Pentadecanal- & 0.12 & - & - & Decanediamide, N, N'-di-benzoyloxy- & - & 0.39 & - \\
\hline $\begin{array}{l}2,2,3,3,4,4 \text { Hexadeutero } \\
\text { Octadecanal }\end{array}$ & 0.146 & - & - & p-Xylene & - & & 0.352 \\
\hline Total: 104 & 52 & 48 & 52 & & - & - & - \\
\hline
\end{tabular}



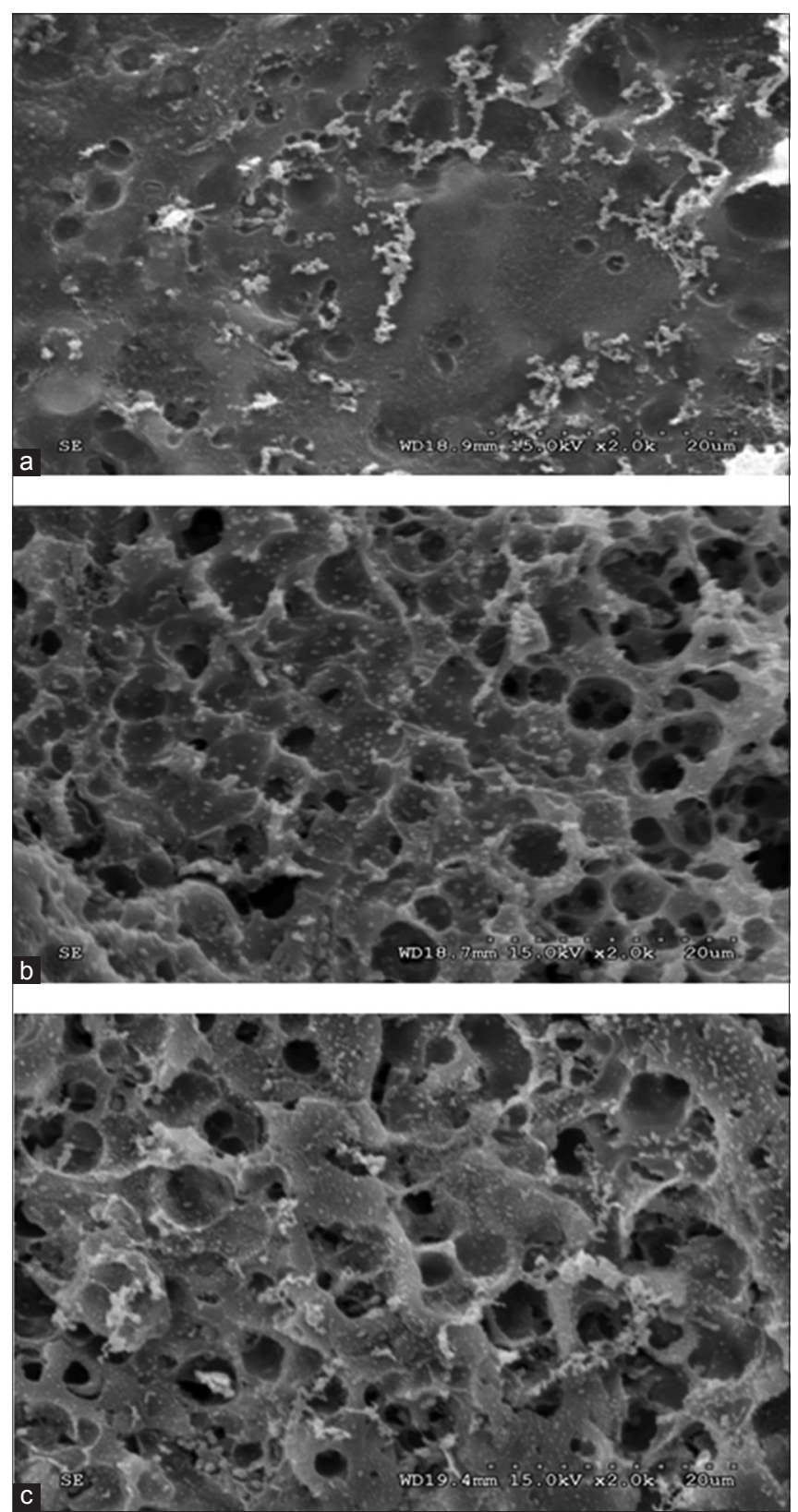

Fig 4. Scanning electron micrographs of cheese obtained with different kinds of rennet. (a) D. sinensis Hemsl. Protease; (b) calf rennet (CR); (c) microbial rennin (MR).

Table 3: Texture profile analysis of cheese made with $D$. sinensis Hemsl. Protease (DHP), calf rennet (CR) and microbial rennin (MR)

\begin{tabular}{lccc}
\hline Indicators & DHP & CR & MR \\
\hline Hardness $(\mathrm{g})$ & $11060 \pm 15.8^{\mathrm{b}}$ & $12153 \pm 26.1^{\mathrm{a}}$ & $10085 \pm 21.5^{\mathrm{c}}$ \\
Adhesiveness $(\mathrm{g} \cdot \mathrm{sec})$ & $-22.78 \pm 2.01^{\mathrm{a}}$ & $-31.7 \pm 1.37^{\mathrm{b}}$ & $-1.587 \pm 1.01^{\mathrm{c}}$ \\
Springiness $(\mathrm{mm})$ & $0.815 \pm 0.02^{\mathrm{b}}$ & $0.769 \pm 0.10^{\mathrm{c}}$ & $0.878 \pm 0.05^{\mathrm{a}}$ \\
Cohesiveness & $0.432 \pm 0.13^{\mathrm{a}}$ & $0.454 \pm 0.08^{\mathrm{a}}$ & $0.431 \pm 0.11^{\mathrm{a}}$ \\
Gumminess & $4777.92 \pm 32.1^{\mathrm{b}}$ & $5793.2 \pm 13.3^{\mathrm{a}}$ & $4377.0 \pm 23.6^{\mathrm{c}}$ \\
Chewiness & $3894.0 \pm 25.6^{\mathrm{b}}$ & $4985.8 \pm 30.1^{\mathrm{a}}$ & $3846.1 \pm 14.1^{\mathrm{c}}$ \\
Resilience & $0.171 \pm 0.03^{\mathrm{b}}$ & $0.168 \pm 0.05^{\mathrm{ab}}$ & $0.174 \pm 0.02^{\mathrm{a}}$ \\
\hline
\end{tabular}

aMeans of the same parameter in the same row without a common superscript letters $(a-c)$ differ significantly $(p<0.05)$ groups. This protease can degrade $\alpha$-CN to the highest extent. This protease can also promote the formation of the network structure of protein and can produce more amino acids. Fifty-two flavor compounds, including volatile acids and carbonyl compounds, are the major source of the specific taste of cheese. Texture profile analysis indicated that the resilience parameters of cheese made by DHP was $0.171 \mathrm{~g}(P>0.05)$. Properties such as elasticity and chewiness were significantly, which hardness and elastic parameters were $11060 \mathrm{~g}$ and $0.815 \mathrm{~cm}(P<0.05)$. TPA revealed that the produced cheese exhibited good flexibility and strong resistance to deformation. Therefore, the produced cheese with DHP can maintain better completeness. With a small pore diameter on the cross section and a dense network structure, the cheese was compact and smooth. The results of protein degradation, flavor compounds, and microstructure features of mozzarella cheese received in this study indicated that $D$. sinensis Hemsl. protease is suitable for mozzarella cheese production.

\section{Author contributions}

Hongyan Wang: Did the analysis and wrote the article, carryed out overall experiments. Yujing Wang: Was involved in most of field experiments and collection data. Aixiang Huang: Designed the study and involved in overall planning, supervision and critical revision.

\section{REFERENCES}

Ahmed, I. A. M., I. Morishima, E. E. Babiker and N. Mori. 2009a Characterisation of partially purified milk-clotting enzyme from Solanum dubium Fresen seeds. Food Chem. 116: 395-400.

Ahmed, I. A. M., I. Morishima, E. E. Babiker and N. Mori. 2009b. Dubiumin, a chymotrypsin-like serine protease from the seeds of Solanum dubium Fresen seeds. Phytochemistry. 70: 483-491.

Ahmed, N.H., M. El-Soda, A. N. Hassan and J. Frank. 2005. Improving the textural Properties of an acid-coagulated (Karish) cheese using exopolysaccharide producing cultures. J. LWT Food Sci. Technol. 38(8): 843-847.

Ali, B., K. Y. Khan, H. Majeed, L. Xu, F. Wu, H. Tao and X. Xu. 2017. Imitation of soymilk-cow's milk mixed enzyme modified cheese: Their composition, proteolysis, lipolysis and sensory properties. J. Food Sci. Technol. 54(5): 1273-1285.

Andrews, A. T. 1983. Proteinases in normal bovine milk and their actions on casein. J. Dairy Res. 50: 45-55.

Ayala-Bribiesca, E., M. Lussier, D. Chabot, S. L. Turgeon and M. Britten. 2016. Effect of calcium enrichment of Cheddar cheese on its structure, in vitro digestion and lipid bioaccessibility. Int. Dairy J. 53: 1-9.

Ben Amira, A., S. Besbes, H. Attia and C. Blecker. 2017. Milk-clotting properties of plant rennet and their enzymatic, rheological, and sensory role in cheese making: A review. Int. J. Food Prop. 44: 1-18.

Cao, Y., J. Zhao and Y. L. Xiong. 2016. Coomassie brilliant bluebinding: A simple and effective method for the determination of water-insoluble protein surface hydrophobicity. Anal. Methods. 8(4): 790-795. 
Delgado, F. J., J. Gonzalez-Crespo, R. Cava and R. Ramírez. 2011. Free fatty acids and oxidative changes of a raw goat milk cheese through maturation. Food Chem. 76(4): C699-C673.

Pontual, E. V., B. E. A. Carvalho, R. S. Bezerra, L. C. B. Coelho, T. H. Napoleão and P. M. G. Paiva. 2012. Caseinolytic and milkclotting activities from Moringa oleifera flowers. Food Chem. 135(3): 1848-1854.

Fang, X., L. E. Rioux, S. Labrie and S. L. Turgeon. 2016. Commercial cheeses with different texture have different disintegration and protein/peptide release rates during simulated in vitro digestion. Int. Dairy J. 56: 169-178.

Galán, E., F. Prados and A. Pino. 2008. Influence of different amounts of vegetable coagulant from cardoon Cynara cardunculus and calf rennet on the proteolysis and sensory characteristics of cheeses made with sheep milk. Int. Dairy J. 18: 93-98.

George, A. B. 2004. Fenaroli's Handbook of Flavor Ingredients, $5^{\text {th }}$ ed. CRC Press, Boca Raton, London, New York, Washington, DC.

Gómez-Ruiz, J. A., L. Cabezas, I. Martinez-Castrol, M. A. GonzálezViñas and J. M. Poveda. 2008. Influence of a defined-strain starter and Laerobacillus plantarum as adjunct culture on volatile compounds and sensory characteristics of Manchego cheese. Eur. Food Res. Technol. 227(I): 181-190.

Gómez, R., E. Sánchez, M. Vioque, J. Ferreira, L. Tejada and J. Fernández-Salguero. 2001. Microbiological characteristics of ewes' milk cheese manufactured using aqueous extracts of flowers from various species of cardoon Cynara L. Milchwissenschaft. 56: 16-19.

Huang, X. W., L. J. Chen and Y. B. Luo. 2011. Purification, characterization, and milk coagulating properties of ginger proteases. J. Dairy Sci. 94: 2259-2269.

Ivana, P., G. Pétrone and A. R. L. Piero. 2014. A kiwi juice aqueous solution as coagulant of bovine milk and its potential in Mozzarella cheese manufacture. J. Food Bioprod. Process. 92: 67-72.

Jooyandeh, H., M. Goudarzi, H. Rostamabadi and M. Hojjati. 2017. Effect of Persian and almond gums as fat replacers on the physicochemical, rheological, and microstructural attributes of low-fat Iranian white cheese. Food Sci. Nutr. 5(3): 669-677.

Ma, Y. 2013. Studies on Protease in Dregea sinensis (Hemsl.) And its Milk-Clotting Property. MS Thesis, Yunnan Agricultural University, Yunnan, China.

McCarthy, C. M., P. M. Kelly, T. P. M. Guinee and G. Wilkinson. 2017. Effect of fat and salt reduction on the changes in the concentrations of free amino acids and free fatty acids in Cheddar-Style cheeses during maturation. J. Food Compost. Anal. 59: 132-140.

Merheb-Dini, C., K. S. Chaves, E. Gomes, R. da Silva and M. L. Gigante. 2016. coalho cheese made with protease from thermomucor indicae-seudaticae N31: Technological potential of the new coagulant for the production of high-cooked cheese. J. Food Sci. 81(3): C563-C568.

Moni, K., A. Sharma and M. V. Jagannadham. 2012. Religiosin B, a milk-clotting serine protease from Ficus religiosa. Food Chem. 131: 1295-1303.

Pontual, E. V., B. E. A. Carvalho, R. S. Bezerra, L. C. B. Coelho, T. H. Napoleão and P. M. G. Paiva. 2012. Caseinolytic and milkclotting activities from Moringa oleifera flowers. Food Chem. 135(3): 1848-1854.

Saint-Eve, A., C. Lauverjat, C. Magnan, I. Déléris and I. Souchon. 2009. Reducing salt and fat conten-t: Impact of composition, texture and cognitive interactions on the percepti-on of flavoured model cheeses. Food Chem. 116(1): 167-175.

Su, H. P., M. J. Huang and H. T. Wang. 2009. Characterization of ginger proteases and their potential as a rennin replacement. J. Sci. Food. Agric. 89(7): 1178-1185.

Tao, L. 2014. Preliminary Studies on Protease in Dregea sinensis (Hemsl.) Characteristics and its Milk-Clotting Mechanism. MS Thesis, Yunnan Agricultural University, Yunnan, China.

Wu, Z. 2003. Flora of Yunnan, Science Press, Beijing, China.

Xue, L. 1994. New Biological Records of Dali, Yunnan People's Publishing House, Kunming, Yunnan, China, pp. 356-357.

Zhang, Y., W. Hongyan and H. Aixiang. 2015. Milk-clotting mechanism of Dregea sinensis Hemsl. Protease. J. Dairy Sci. 98: 8445-8453.

Zisu, B. and N. P. Shah. 2007. Texture characteristics and pizza bake properties of low-fat Mozzarella cheese as influenced by pre-acidification with citric acid and use of encapsulated and ropy exopolysaccharide producing cultures. Int. Dairy J. 17(8): 985-997. 